\title{
LISSAUER FORM OF PARETTC NEUROSYPHILIS WITH A CEREBRAL MASS LESION
}

\author{
RICARDO NITRINI* - ANTONIO A. ZAMBON * - ROBERTO HIRSH * \\ SERGIO ROSEMBERG ** - M. SCAFF*
}

SUMMARY - A 40-year-old male patient with progressive dementia presented adversive seizures, and CT scan showed an enlarging focal mass lesion in the right cerebral hemisphere. Cerebrospinal fluid examination and brain biopsy confirmed the diagnosis of neurosyphilis. After a course of penicillin therapy there was disappearance of the cerebral mass lesion and the CT scan showed focal atrophy in the right cerebral hemisphere. This case suggests that Lissauer form of paretic neurosyphilis may present as a focal mass lesion.

\section{Forma de Lissauer da paralisia geral progressiva com lesão expansiva cerebral.}

RESUMO - Registro de caso de paciente do sexo masculino com 40 anos de idade em que a tomografia computadorizada revelou a presença de processo expansivo no hemisfério cerebral direito. Os exames do líqüido cefalorraqueano e biópsia cerebral evidenciaram as caracteristicas de neurossifinis. Após penicilinoterapia foi constatada atrofia focal no hemisfério cerebral direito. Este caso sugere que a forma de Lissauer da paralisia geral progressiva pode manifestar-se como processo expansivo cerebral.

The Lissauer form of paretic neurosyphilis is characterized by focal neurological signs in addition to mental deterioration 1,11. The more common signs are hemiparesis, aphasia and partial seizures. Pathologically there is cortical and subcortical atrophy together with focal atrophy, usually unilateral, centered around the temporal and inferior parietal lobes 1-7. The CT scan in such cases shows the atrophic processses $\mathbf{1 , 5 , 1 2}$.

We report a case of Lissauer form of paretic neurosyphilis with a focal mass lesion in the right cerebral hemisphere.

\section{CASE REPORT}

O.S.D., a 40-year-old man was admitted to the Neurological Division in March 1986. For two years there was a progressive change in his behavior, which was characterized by outbursts of aggression and persecutory delusions. Six months before admission he developed megalomaniac delusions and was referred to psychiatric treatment. Ten days before admission he had adversive seizures to the left side. A CT scan demonstrated a zone of contrast enhancement in the paramedian region of the right frontal lobe. His general physical examination was normal. Mental status testing revealed psychic agitation, severe memory disturbances and spatial and temporal disorientation. Neurological examination revealed only paratonic rigidity in the arms and in the legs, more intense in the left side. Routine laboratory examination was normal. Electroencephalogram showed continuous slow-wave activity in the right hemisphere, mainly in the frontal region. CT scan revealed slight contrast enhancement in the paramedian region of the right frontal lobe surrounded by an area of decreased attenuation interpreted as edema causing compression of the right lateral ventricle (Fig. 1A). Cerebrospinal fluid (CSF) examination revealed a protein of $96 \mathrm{mg} / \mathrm{dl}$, glucose of $51 \mathrm{mg} / \mathrm{dl}$ and 41 leukocytes $/ \mathrm{mm}^{3}$ ( $39 \%$ lymphocytes, $30 \%$ monocytes, $25 \%$ neutrophils, $4 \%$ macrophages, $2 \%$ plasma cells). Electrophoresis of $\mathrm{CSF}$ proteins revealed $25.4 \%$ of gammaglobulins. The Wassermann, VDRL, FTA-Abs and IgM-solid-phase haemadsorption reactions were positive in the blood and in the CSF. The patient was treated with penicillin

Departments of Neurology *and Pathology**, Faculty of Medicine, São Paulo Universfty. 
G (24 millions units intravenous dally for 20 days). There was progrcssive improvement of the mental status during the treatment, and the neurologic examination remained unchanged. On the 18th day of penicillin treatment a CT scan revealed a large area of decreased attenuation involving the white matter of the frontal, temporal and parietal lobes of the right hemisphere compressing the right lateral ventricle and causing a sight shift of the medial structures to the left slde (Fig. 1B). Cerebral angiography showed a mass effect in the left cerebral hemtsphere. A biopsy of the right anterior frontal lobe and of the meninges revealed a subacute encephalitis characterized by perivascular cuffing of lymphocytes, slight

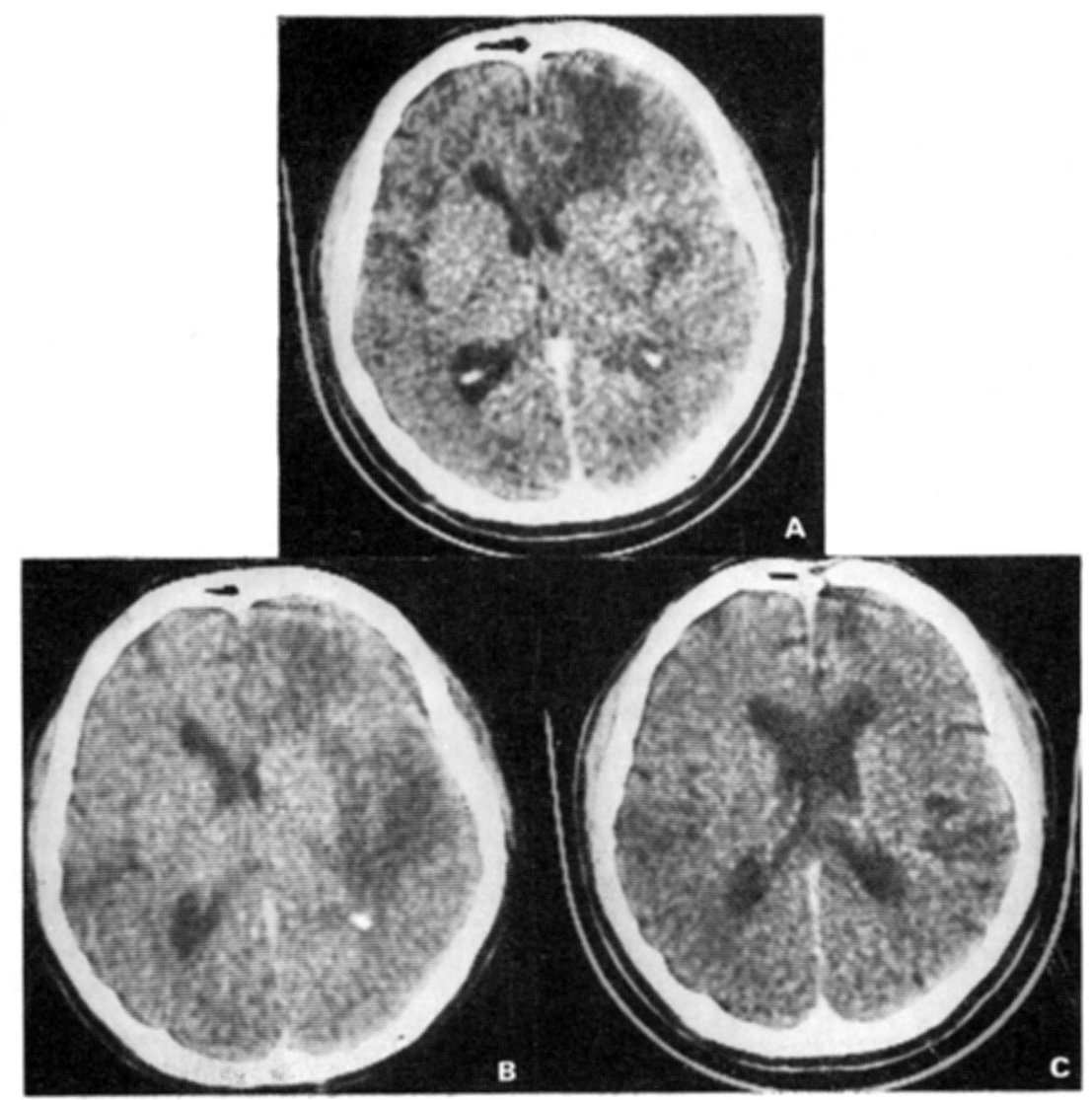

Fig. 1 - Case O.S.O.: C'T scans. A, before penicillin therapy demonstrating slight contrast enhancement in the paramedian region of the right frontal lobe surrounded by an area of decreased attenuation. $B$, on the 18th day of penicillin therapy enhanced CT shows a large area of decreased attenuation involving the white mater of the right cerebral hemisphere. $C$, nine months after penicillin therapy enhanced $C T$ shonos atrophy in the right frontal and temporal lobes.

loss of neurones of the cortex and microglfal proliferation with rod cell formation (Fig. 2); in the subcortical white matter there were edema and numerous gemistocytic astrocytes. The meninges were thickened and infiltrated with lymphocytes; Treponema pallidum was not found. The mental status improved after the treatment but an intense fixation amnesia remained. One month after the treatment has ceased a CT scan showed mild generalized atrophy and discrete zones of decreased attenuation in the right frontal and temporal lobes. A CSF examination revealed a protein of $54 \mathrm{mg} / \mathrm{dl}$, glucose of $58 \mathrm{mg} / \mathrm{dl}$ and 41 eukocytes $/ \mathrm{mm} 3$. Electrophoresis of CSF proteins revealed $30.7 \%$ of gammaglobulins with oligocional bands. The Wassermann, VDRL and FTA-Abs reactions were still positive in the blood and in the CSF. Nine months after treatment the fixation amnesia was unchanged. A CT scan snowed 

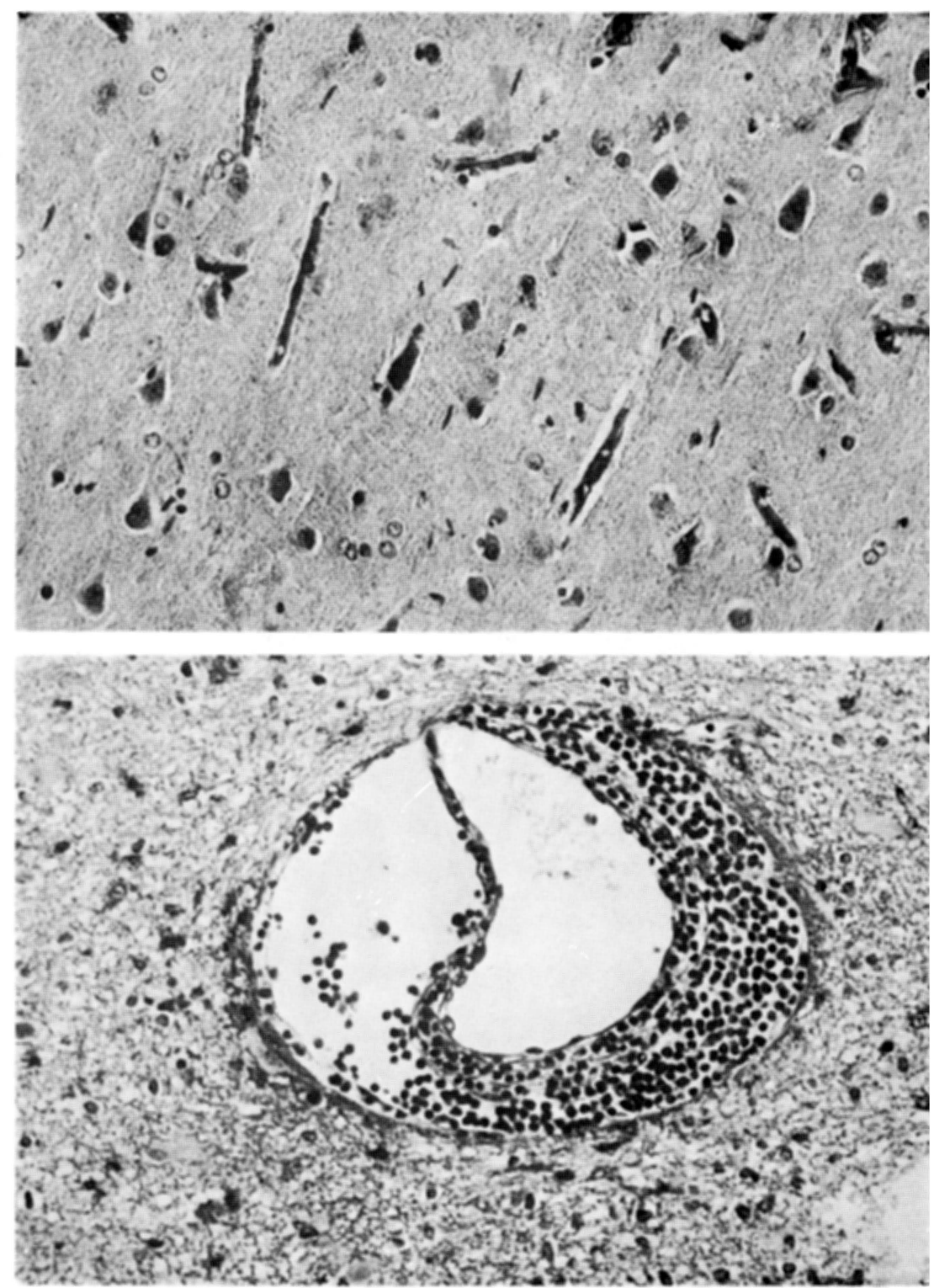

Fig. 2 - Case O.S.O.: right anterior frontal lobe biopsy. Above: cerebral cortex; note neuronal loss, astrogliosis and rod cell proliferation (HE, 264X). Below: perivascular cuffing of mononuclear cells in superficial white matter (HE, 264X).

mild generalized atrophy and Iocalized atrophies in the right frontal and temporal lobes (Fig. 1C). A CSF examination revealed normal protein and glucose contents, and normal cell count; the Wassermann, VDRL and FTA- $\mathbf{F b}$ reactions were still positive.

\section{COMMENTS}

This 40-year-old man presented with a chronic and progressive change of behavior whith persecutory and megalomaniac delusions. The adversive seizures and the CT finding of a right frontal lesion were interpreted initially as indicative of a cerebral tumor. The CSF findings were typical for neurosyphilis, the evolution was suggestive of paretic neurosyphilis, and the brain biopsy supported this diagnosis. 
CT findings are different in the several clinical forms of neurosyphilis. In meningovascular syphilis areas of decreased attenuation with or without contrast enhancement have been described 4,5. In the rare gummas of the central nervous system areas of increased or decreased attenuation sometimes with mass effect have been reported 2-8. The usual CT finding of paretic neurosyphilis is cortical and subcortical atrophy more intense in the frontal regions 12 . Kulla et al. 10 reported a case of neurosyphilis with a large area of decreased attenuation involving the left frontal and temporal white matter causing a slight mass effect. Cerebral angiography did not show arterial stenosis or obstruction. The diagnosis of Lissauer form of paretic neurosyphilis was suggested.

Seizures are the more common early focal sign in Lissauer form of paretic neurosyphilis, and hemiplegia, aphasia, apraxia or hemianopsia may follow immediatelly or come on more gradually 7,11. Adversive seizures were the only clear clinical focal sign in our case but the $\mathrm{CT}$ findings demonstrated a diffuse and progressive alteration of the white matter of the right hemisphere. The lesion was not confined to an arterial territory and the lack of clinical deterioration during its development did not support the hypothesis of a main arterial branch occlusion. The cerebral angiography did not show arteritic changes of neurosyphilis. The lesion remitted without other treatment besides penicillin, and the $\mathrm{CT}$ findings 9 months after treatment were consistent with the diagnosis of Lissauer form of paretic neurosyphilis. The brain biopsy of our case did not show the typical changes of Lissauer form of paretic neurosyphilis. This could be due to the momentum of the biopsy or to its small size. It is possible that the more typical changes appear later in the evolution of the process.

The pathogenesis of the focal atrophy of Lissauer form of paretic neurosyphilis is not clear 3,7. Merritt and Springlova 11 proposed that the focal atrophy is produced by a combination of functional disturbance of circulation and the pathological process of paretic neurosyphilis. The CT findings of short-lived focal mass lesions in our case and in the case reported by Kulla et al.10 suggest that in this form of neurosyphilis there is a transient disorder of the cerebral circulation or metabolism. The penicillin treatment may have shortened the evolution of the cerebral changes in these cases but it is possible that at least in some cases of Lissauer form of paretic neurosyphilis the focal atrophic process is preceded by a transient phase of cerebral mass lesion.

\section{REFERENCES}

1. Cohen MS, Gibson G, Olarte MR - Lissauer form of paretic neurosyphilis: forgotten but not gone. Ann Neurol 12:219, 1982.

2. Eltomey AA, Olin MS, Roberts MP - Cerebellopontine angle gumma. Neurosurgery $15: 252,1984$.

3. Escobar A, Nieto D - Neurosyphilis. In Minckler J (ed): Pathology of the Nervous System. McGraw-Hill, New York, 1972, pg 2448.

4. Gabay EL, Hallinan J, Lovett MA - Computerized tomographic findings in meningovascular syphilis: a case report. Sex Transm Dis 10:39, 1983.

5. Godt P, Stoeppler L, Wischer U, Schroeder HH - The value of computed tomography in cerebral syphilis. Neuroradiology 18:197, 1979.

6. Goulon M, Raphael JC, Chesneau AM, Brunel D, Lamer C - Gomme syphilitique cérébrale operée. Rev Neurol (Paris) 142-228, 1986.

7. Greenfield JG - Infectious diseases of the central nervous system. In Blackwood $W$ et al. (eds): Greenfield's Neuropathology. Edward Arnold, London, 1971, pg 138.

8. Hwang WZ, Hasegawa $\mathrm{T}$, Ito $\mathrm{H}$, Shimoji $\mathrm{T}$, Yamamoto $\mathrm{S} \rightarrow$ Cerebral gumma: case report. J Neurosurg 63:301, 1985.

9. Kaplan JG, Sterman AB, Horoupian D, Leeds NE, Zimmerman RD, Gade $R$ - Luetic meningitis with gumma: clinical, radiographic and neuropathologic features. Neurology 31:464, 1981.

10. Kulla L, Russel JA, Smith 'TW, Zito Jr, Davidson $\mathrm{R}-$ Neurosyphilis presenting as a focal mass lesion: a case report. Neurosurgery 14:234, 1984.

11. Merritt HH, Springlova M - Lissauer's dementia paralytica: a clinical and pathological study. Arch Neurol Psychiat 27:987, 1932.

12. Michel $\mathbf{D}$, Blanc $\mathbf{A}$, Laurent $\mathbf{B}$, Foyatier $\mathbf{N}$, Portafaix $\mathbf{M}-$ Etude biologique, psychométrique et tomodensimétrique de la neurosyphilis traitée. Rev Neurol (Paris) 139:737, 1983.

13. Punt J - Multiple cerebral gummata: case report. J Neurosurg 58:959, 1983. 